\title{
Phytotherapy and intraoperative floppy iris syndrome: the implications
}

Eye (2017) 31, 823-826; doi:10.1038/eye.2017.16; published online 3 March 2017

\section{Introduction}

Intraoperative floppy iris syndrome (IFIS) was first recognised and described in 2005. ${ }^{1,2}$ It is characterised by poor pupil dilatation, billowing of iris stroma, iris prolapse through corneal incisions, and progressive intraoperative pupillary constriction. ${ }^{1}$ The incidence of IFIS can vary, representing between $2-3 \%$ of the entire cataract population, but it can be $>50 \%$ in patients taking Tamsulosin-a selective $\alpha_{1}$-adrenergic blocker, compared to other nonselective $\alpha$-adrenergic blockers such as Alfuzosin, Doxazosin, and Terazosin. 1,3,4

Alpha-adrenergic antagonists are commonly used in the treatment of benign prostate hyperplasia (BPH). ${ }^{5}$ The last few years have seen a rise in the use of herbal treatment for $\mathrm{BPH}$, with Saw Palmetto being the most common herbal alternative treatment. Saw Palmetto has been shown to have an $\alpha$-adrenergic effect. ${ }^{6}$ As herbal medications and supplements are often not considered as medications by the patients and thus omitted during history taking unless directly prompted to do so, it is important for the surgeon to be aware of all medications and supplements that could potential cause IFIS. ${ }^{7}$

\section{Aim \\ To assist in this process, we examined the contents, names, and indications of commonly encountered herbal remedies containing $\alpha$ - adrenergic blockers in Europe, United States, and Australia.}

\section{Materials and methods}

We performed an internet-based study looking at all pharmacy and health food store chains of major European countries, United States,
Australia, and New Zealand. The European sites used were from the United Kingdom, France, Germany, Spain, and Greece.

\section{Results}

The names of the herbal remedies, indications for their use, and their contents and active ingredients are summarised in Tables 1 and 2 .

The main indication for these herbal remedies was BPH followed by hair loss, reproductive health and fertility, migraine, and their use as a herbal aphrodisiac. The commonest active ingredient was Saw Palmetto followed by Pygeum. Saw Palmetto concentration ranged between $160 \mathrm{mg}$ and $4 \mathrm{~g}$. Pygeum concentration ranged between 5 and $100 \mathrm{mg}$.

\section{Discussion}

In recent years, herbal remedies are becoming increasingly popular for the treatment of medical conditions including BPH. In Germany and other European countries, herbal medication has become the first-line treatment for mild to moderate symptoms of BPH. ${ }^{6}$

The most common herbal medication used for $\mathrm{BPH}$ is American dwarf palm, also known as Serenoa repens or Saw Palmetto. Its mode of action is complex as it is thought that it exerts an effect through various pathways. It has been reported that it bears an $\alpha$-adrenergic antagonistic effect and can potentially increase the risk of IFIS. ${ }^{6-8}$ In 2002, a survey examining the use of complementary and alternative medication found that, in the United States, $18.9 \%$ of age-adjusted adults use complementary products, and of these, $5.8 \%$ use Saw Palmetto. $^{9}$

Rye grass pollen extract commonly known with its commercial name Cernilton (also as ProstaBrit in the United Kingdom) relaxes urethral smooth muscle tone and increases bladder muscle contraction. It has been shown to have an anti- $\alpha$-adrenergic action. ${ }^{10}$ 
Table 1 Herbal remedies containing $\alpha$-adrenergic blockers in Europe

\begin{tabular}{|c|c|c|}
\hline Product & Doses & Indication \\
\hline \multicolumn{3}{|l|}{ United Kingdom } \\
\hline Saw Palmetto capsules & 80,320 , and $450 \mathrm{mg}$ & Symptoms of BPH \\
\hline \multicolumn{3}{|l|}{ Protace (WellMan) } \\
\hline Multivitamins & Contains: Saw Palmetto (160 mg) & Hair loss+nutritional supplement \\
\hline \multicolumn{3}{|l|}{ Nanogen (men over $40+$ ) } \\
\hline Multivitamins & Contains: Saw Palmetto (160 mg) & Hair loss+nutritional supplement \\
\hline Multivitamins & Contains: Saw Palmetto extract and Pygeum extract & Symptoms of BPH \\
\hline \multicolumn{3}{|l|}{ Formula 600 Plus for men (PSC) } \\
\hline \multicolumn{3}{|l|}{ Germany } \\
\hline \multirow[t]{3}{*}{ Saw Palmetto capsules } & $120,540,550,100$, and $2500 \mathrm{mg}$ & Symptoms of benign prostate hyperplasia \\
\hline & & Reproductive health and fertility \\
\hline & & Hair loss \\
\hline Pygeum africanum capsules & $100 \mathrm{mg}$ & Symptoms of $\mathrm{BPH}$ \\
\hline Multivitamins & Contains: Pygeum extract & Symptoms of BPH \\
\hline \multicolumn{3}{|l|}{ Prostate Health (Biovea) } \\
\hline Multivitamin & Contains: Saw Palmetto and Pygeum extract & Symptoms of BPH \\
\hline \multicolumn{3}{|c|}{ Saw Palmetto Complex (Newton-Everett Biotech) } \\
\hline \multicolumn{3}{|l|}{ France } \\
\hline \multirow[t]{2}{*}{ Saw Palmetto capsules } & $160,295,300,320$, and $1010 \mathrm{mg}$ & Symptoms of BPH \\
\hline & & Hair loss \\
\hline Pygeum capsules & 100 and $250 \mathrm{mg}$ & Symptoms of BPH \\
\hline Multivitamin & Contains: Saw Palmetto (60 mg) & Symptoms of $\mathrm{BPH}$ \\
\hline Prostata' Home (Dieti Naura Co.) & Contains: Saw Palmetto and Pygeum extract & \\
\hline \multicolumn{3}{|l|}{ Sabal/Pygeum (Gph Diffusion) } \\
\hline \multicolumn{3}{|l|}{ Spain } \\
\hline \multirow[t]{3}{*}{ Saw Palmetto capsules } & 300 and $550 \mathrm{mg}$ & Symptoms of benign prostate hyperplasia \\
\hline & & Hirsutism \\
\hline & & Herbal aphrodisiac \\
\hline Multivitamins & Multiple ingredients including: Saw Palmetto & Hair loss \\
\hline \multicolumn{3}{|l|}{ Lambdapil (ISDIN) } \\
\hline \multicolumn{3}{|l|}{ Prosor (Soria Natural) } \\
\hline Combination therapy & Multiple ingredients including: Saw Palmetto (30 mg) & Symptoms of BPH \\
\hline Prosavital (Health Aid) & Pygeum $(5 \mathrm{mg})$ & \\
\hline Combination therapy & Multiple ingredients including: Saw Palmetto $(80 \mathrm{mg})$ & Symptoms of BPH \\
\hline Saw Palmetto (Nature's Bounty) & Pygeum $(10 \mathrm{mg})$ & \\
\hline \multicolumn{3}{|l|}{ Greece } \\
\hline Saw Palmetto capsules & 300 and $320 \mathrm{mg}$ & Symptoms of BPH \\
\hline
\end{tabular}

Pygeum africanum, the extract of the African prune tree is used to treat lower urinary tract symptoms. It can be used alone or in combination with Saw Palmetto. ${ }^{11}$ Pygeum improves the symptoms of BPH through its effects on bladder contractility, anti-inflammatory action, inhibition of fibroblast production, and endocrine effect, but no effect on the $\alpha$-adrenergic receptors has been reported. ${ }^{11}$

An interesting and slightly surprising fact of our study is that the indications for the use of these $\alpha_{1}$-antagonistic herbal supplements are very variable. This may be due to the use of some of these supplements as traditional remedies or the more 'holistic' treatment perception associated with herbal remedies. Although Saw Palmetto and other herbal remedies have been used for a variety of indications separately, their combination, that is, Saw Palmetto with Pygeum was solely used for the treatment of BPH.

Plant extracts are more complex than synthetic compounds and exert their therapeutic action often through more than one pathway and their mode of action is often elusive. Phytotherapy is becoming increasingly popular to treat an array of medical conditions, and the possibility of a patient self-medicating with a substance that can affect iris tone and cause IFIS is ever increasing.

IFIS has been associated with an increased risk of intraoperative complications during intraocular surgery such as iris prolapse through surgical wounds, increasing pupillary miosis during surgery, iris trauma, and an increased risk of posterior capsule rupture with vitreous loss. ${ }^{12,13}$ Chang et al ${ }^{1}$ reported an increased risk of posterior capsular rupture in their IFIS group patients recording a rate of $12 \%$. Recognition of the risk factors associated with IFIS allows the surgeon to prepare preoperatively and reduce the risk of unexpected intraoperative surprises. Predicting which patients are at risk of IFIS is crucial at pre-assessment and at the preoperative ward round. 
Table 2 Herbal remedies containing $\alpha$-adrenergic blockers in United States, Australia and New Zealand

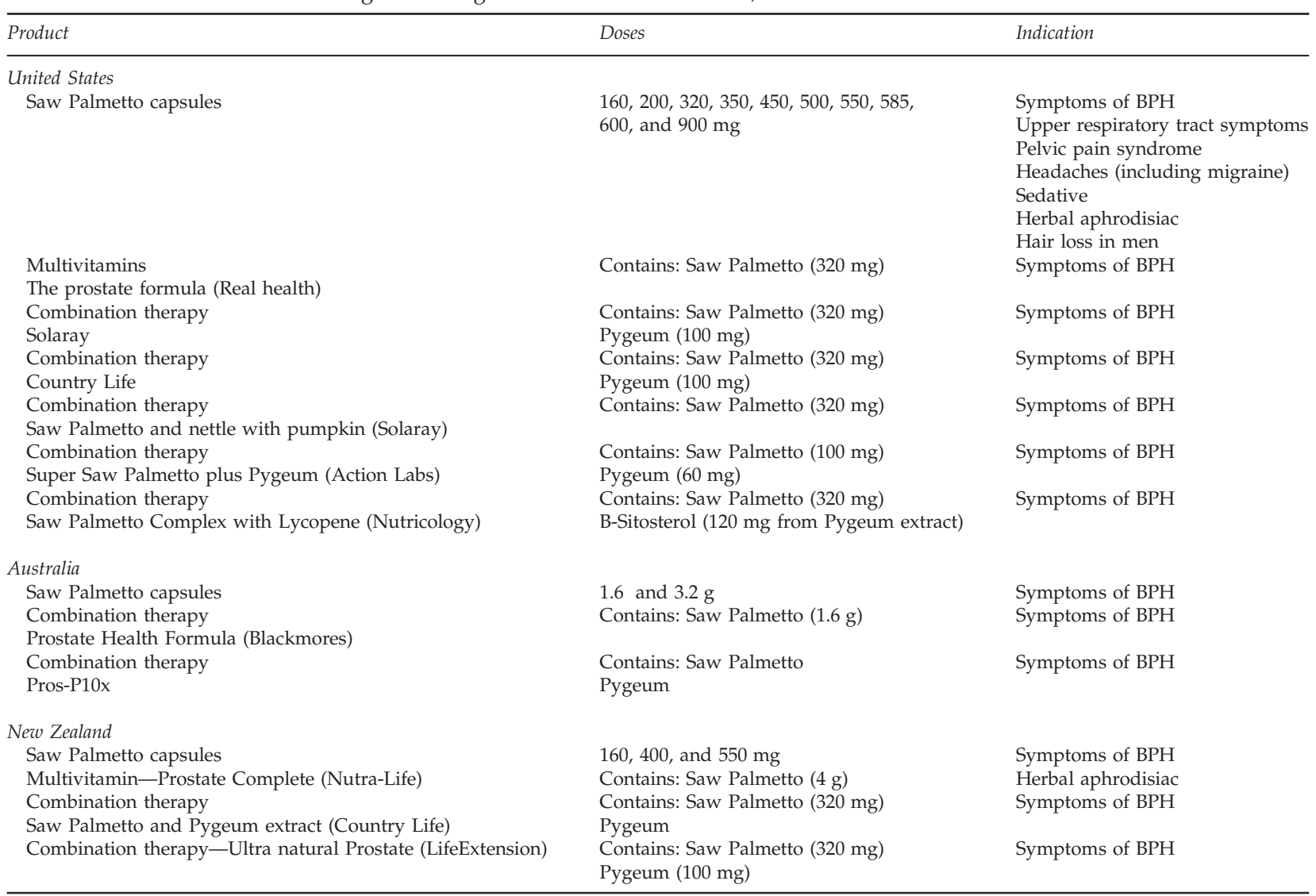

The association between IFIS and the use of $\alpha$-antagonists is established. The consensus is that urologists should not change their prescribing habits, but should consider informing the patient's ophthalmologist especially if the patient has been diagnosed with cataracts or cataract surgery has been planned. ${ }^{14}$ Studies examining the effect of herbal medication on iris tone are limited, but there has been a suggested risk of IFIS through an $\alpha$-adrenergic pathway, similar to that of Tamsulosin. ${ }^{6-8}$ To our knowledge, no study has examined the effect of herbal medications cessation to iris tone, but one would assume that effect to be similar to that of Tamsulosin cessation. ${ }^{9}$ Adopting an awareness policy similar to that for pharmaceutical medication should suffice.

A point to stress is that our study highlights a broad use of $\alpha$-adrenergic antagonistic herbal supplements from $\mathrm{BPH}$ to hair and used as a natural aphrodisiac. With the ever growing population's life expectancy, the need for efficient and complication-free cataract surgery will continue to grow. The anticipation and prediction of IFIS risk can help the operating surgeon minimise the intraoperative complications and lead to safer surgery with increasingly successful outcomes. Patients often do not consider herbal remedies and vitamins to be medication, and therefore fail to mention them unless directly prompted to do so. Our recommendation is that patients should be directly asked about the use of alternative therapies for recreation or medicinal purposes, and for the clinician or pre-assessment nurse to be aware of specific formulations that are or could potentially be associated with increased surgical risk and possibly a compromised surgical outcome.

\section{Conflict of interest}

The authors declare no conflict of interest.

\section{References}

1 Chang DF, Campbell JR. Intraoperative floppy iris syndrome associated with tamsulosin. J Cataract Refract Surg 2005; 31 (4): 664-673.

2 Parssisen $\mathrm{O}$. The use of tamsulosin and iris hypotony during cataract surgery. Acta Opthalmol Scand 2005; 83(5): 624-626.

3 Blouin MC, Blouin J, Perreault S, Lapointe A, Dragomir A. Intraoperative floppy-iris syndrome associated with alpha1adrenoreceptors: comparison of tamsulosin and alfuzosin. J Cataract Refract Surg 2007; 33(7): 1227-1234. 
4 Chatziralli IP, Sergentanis TN. Risk factors for intraoperative floppy iris syndrome: a meta-analysis. Ophthalmology 2011; 118(4): 730-735.

5 Lowe FC. Role of the newer alpha adrenergic-receptor antagonists in the treatment of benign prostatic hyperplasiarelated lower urinary tract symptoms. Clin Ther 2004; 26: 1713.

6 Dreikorn K. Complementary and alternative medicine in urology. BJU Int 2005; 95: 1177-118.

7 Neff KD, Sandoval HP, Fernández de Castro LE, Nowacki AS, Vroman DT, Soloman KD. Factors associated with intraoperative floppy iris syndrome. Ophthalmology 2009; 116(4): 658-663.

8 Yeu E, Grostern R. Saw palmetto and intraoperative floppyiris syndrome. J Cataract Refract Surg 2007; 33(5): 927-928.

9 Barnes PM, Powell-Griner E, McFann K, Nahin RL. Complementary and alternative medicine use among adults: United States 2002. Adv Data 2004; 343: 1-19.

10 MacDonald R, Ishani A, Rutks I, Wilt TJ. A systematic review of Cernilton for the treatment of benign prostatic hyperplasia. BJU Int 2000; 85: 836-841.

11 Wilt TJ, Ishani A, Rutks I, MacDonald R. Phytotheraphy for benign prostate hyperplasia. Public Health Nutr 2000; 3(4A): 459-472.

12 Chang DF, Braga-Mele R, Mamalis N, Masket S, Miller KM, Nichamin LD et al. ASCRS White Paper: clinical review of intraoperative floppy-iris syndrome. I Cataract Refract Surg 2008; 34(12): 2153-2162.

13 Parssisen O, Leppanen E, Keski-Rahkonen P, Mauriala T, Dugue B, Lehtonen M. Influence of tamsulosin on the iris and its implications for cataract surgery. Invest Ophthalmol Vis Sci 2006; 47: 3766-3771.

14 Zaman F, Bach C, Junaid I, Papatsoris AG, Pati J, Masood J et al. The floppy iris syndrome-what urologists and ophthalmologist need to know. Curr Urol 2012; 6(1): 1-7

M Tsatsos ${ }^{1}$, C MacGregor ${ }^{1}$, I Athanasiadis², M Moschos², A Mataftsi and N Ziakas²

${ }^{1}$ University Hospital Southampton NHS Foundation Trust, Eye Clinic, Southampton, UK

${ }^{2}$ Eye Department, Aristotle University of Thessaloniki, Thessaloniki, Greece

Correspondence: I Athanasiadis, Eye Department, Aristotle University of Thessaloniki, Thessaloniki 541 24, Greece Tel: +30 697708 2256/+44 7766670267 . E-mail: athana1972@yahoo.com 